\title{
Sampling the Volatile Rich \\ Transition Zone at Bermuda: Can \\ Tungsten Stable Isotopes Help Differentiate Recycled Lithologies?
}

\author{
SARAH E. MAZZA ${ }^{1 *}$, ESTEBAN GAZEL $^{2}$, THORSTEN \\ KLEINE $^{3}$ \\ ${ }^{1}$ Department of Geosciences, Smith College, Northampton, \\ MA, USA \\ ${ }^{2}$ Department of Earth and Atmospheric Sciences, Cornell \\ University, Ithaca, NY, USA \\ ${ }^{3}$ Institut für Planetologie, University of Münster, Münster, \\ Germany \\ *correspondance to smazza@smith.edu
}

Intraplate magmatic provinces found away from plate boundaries provide direct sampling of the Earth's mantle composition and heterogeneity. Observed chemical heterogeneities in the mantle are commonly attributed to recycling during subduction, which allows for the addition of volatiles and incompatible elements into the mantle. New geochemical evidence, coupled with seismic-geodynamic modeling, suggests that Bermuda sampled a previously unknown mantle domain stored in the transition zone [1]. Bermuda is characterized by silica undersaturated melts that have significant enrichments in incompatible elements and volatiles, and a unique, extreme radiogenic ${ }^{206} \mathrm{~Pb} /{ }^{204} \mathrm{~Pb}$ isotopic signature. The Bermuda source is interpreted as a new, transient mantle reservoir that resulted from recycling and storage of incompatible elements and volatiles in the transition zone, aided by the fractionation of $\mathrm{Pb}$ in a mineral that is only stable in this boundary layer such as K-hollandite. [1] suggested that recent recycling into the transition zone related to subduction events during the formation of Pangea is the reason why this reservoir has only been found in the Atlantic Ocean.

Tungsten stable isotopes, while still in their infancy, have the potential to record subduction related processes, and thus could help differentiate the recycling of material into the mantle. Ocean island basalts from the traditional HIMU and EM mantle domains record small variations in $\delta^{184} \mathrm{~W}$ (where where $\delta^{184} \mathrm{~W}$ is the \%o deviation from NIST SRM 3163), deviating slightly from chondritic values. These small variations are likely the result from recycling of material with variable $\mathrm{W}$ ratios due to dehydration during subduction [2]. We present new W stable isotope data from Bermuda to help understand the nature of this transition zone source, and found that Bermuda has an average $\delta^{184} \mathrm{~W}$ of $0.033 \pm 0.006$ $\%$.

[1] Mazza et al. (2019) Nature 569, 398-403. [2] Mazza et al. (2020) EPSL 530 . 